\author{
Military Technical College \\ Kobry Elkobbah, Cairo, \\ Egypt.
}

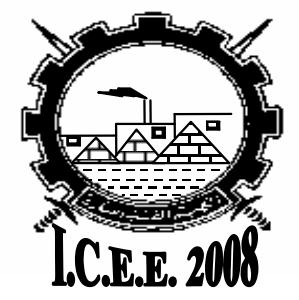

$4^{\text {th }}$ International Conference On

Chemical \& Environmental Engineering

27-29 May 2008

\title{
APPLYING DIFFERENT ADVANCED OXIDATION PROCESSES FOR THE MINERALIZATION OF INDUSTRIAL WASTEWATER: A COMPARATIVE STUDY
}

\author{
Maha A. Tony and ${ }^{*}$ Aghareed M. Tayeb ${ }^{* *}$
}

\begin{abstract}
:
Industry represents an essential source of water pollution. Among the common industries which discharge wastewater is the textile industry. This industry causes environmental pollution including water pollution. To face this problem, recently, a new set of treatment technologies, called Advanced Oxidation Technologies (AOTs), has emerged which, does not only treat but also mineralize organic pollutants. Applying these AOTs in the treatment of the textile industry wastewater effluent is conducted in the present work. Sunlight is used as a source of UV light and the results are compared with those obtained when using an artificial source of UV light. A photo-chemical reactor is used to carry out the experiments. The concentration of the pollutants in the effluent subjected for treatment is followed along the treatment time. The kinetic constants were compared. Values of the kinetic constants of $0.0421,0.031,0.0132$ and 0.0087 were obtained for photo-Fenton, UV/TiO $/ \mathrm{H}_{2} \mathrm{O}_{2}$, $\mathrm{UV} / \mathrm{H}_{2} \mathrm{O}_{2}$ and $\mathrm{UV} / \mathrm{TiO}_{2}$ processes, respectively. Rough cost estimation for different treatment systems clarified that the photo-Fenton's reagent is far cheaper than other AOTs. Finally, the results obtained are used as a basis for suggesting an arrangement for a photo-catalytic treatment plant.
\end{abstract}

\section{KEY WORDS:}

wastewater, titanium dioxide, photo-Fenton catalyst, hydrogen peroxide, photocatalysis, kinetics.

\footnotetext{
Basic Science of Engineering Department, Faculty of Engineering, Menofya University, Menofya, Egypt.

** Chemical Engineering Department, Faculty of Engineering, Minia University, Minia, Egypt.
} 


\section{INTRODUCTION:}

Water is the essential element for life on earth and a key source of humanity and it is abundant on earth. The whole amount of water existing on earth (ocean, lakes, polar regions, glaciers, underground water, water of the biosphere and atmosphere) is around $1.4 \times 10^{9} \mathrm{~km}^{3}$. However, $97.5 \%$ is saltwater. Of the remaining $2.5 \%$, that is fresh water, $70 \%$ is frozen in the polar icecaps; the rest is mainly present as soil moisture or in inaccessible subterranean aquifers. Only less than $1 \%$ of the world's fresh water resources are readily available for human use; and even this resource is very unevenly distributed (WHO, 2002) [1]. Phenols, pesticides, fertilizers and other chemical products are disposed off directly into the environment, without being treated. For this reason, the search for solutions of this problem is an interesting research topic.

The techniques available for the treatment of residue are only for transferring it to a controlled discharge. These methods can be destructive as for example incineration, which only allows the efficient elimination of the pollutant from an aqueous form and it have the problem of releasing intermediate toxins [2, 3].

So, it is clear that, the previous techniques could transfer pollutants from the aqueous phase to another one, but they do not destroy the pollutant. Other techniques may be selective but slow to moderate in destruction rate, or rapid but not selective, thus generating appreciable reactors or energy costs.

Due to these disadvantages advanced oxidation technologies (AOTs), have emerged. These technologies are based on the generation of highly reactive intermediates, which are capable of attacking the organic pollutants and initiating their oxidation and eventual mineralization. They are characterized by a selectivity of attack and are capable of attacking the organic pollutants. Most of the commercially developed advanced oxidation processes (AOPs) are based on the use of ultraviolet light to generate the hydroxyl radicals photo-chemically.

Bauer and Fallmann [4] carried out solar experiments in Vienna in Summer 1995 using AOPs; $\mathrm{O}_{3}, \mathrm{H}_{2} \mathrm{O}_{2}, \mathrm{TiO}_{2}$ and photo-Fenton for the degradation of landfill leachate. The results of these experiments concluded that the latter was far superior to the other methods, since complete TOC-destruction is finished after few minutes. Nansheng and Shizhong, 1996 [5] demonstrated the photo-degradation of different dyes using a UV lamp in a UV/Fe ${ }^{3+}$ system. In addition, Chen et al., 1997 [6], demonstrated that toxic pollutants such as phenols in industrial wastewaters can be eliminated efficiently by photochemical methods using a combination of UV and heterogeneous photo catalyst, and combinations of $\mathrm{UV}, \mathrm{H}_{2} \mathrm{O}_{2}$, and ferric compounds. Emilio et al., 2002 [7], studied the degradation of ethylene diaminetetra-acetic acid (EDTA); by the ferrioxalate $/ \mathrm{H}_{2} \mathrm{O}_{2}$ process under solar irradiation. A rapid (TOC) removal was attained, reaching almost $100 \%$ after $1 \mathrm{~h}$ solar exposure under the best conditions. In order to attain a high TOC removal yield. Will et al., in 2004 [8], studied 
the photo-Fenton oxidation of phenol in aqueous solutions using $\mathrm{Fe}^{2+}, \mathrm{H}_{2} \mathrm{O}_{2}$ and $\mathrm{UV}-$ visible light (sunlight) and in other experiments using artificial light source. The results indicated that the photo-Fenton process using solar irradiation is effective for industrial wastewater containing phenol more than $90 \%$ of TOC.

Although the UV-based AOTs are effective in destroying organic pollutants in contaminated wastewater, they are generally rather expensive and require high levels of electrical energy. AOTs could be developed such that it uses sunlight as the UV light source, thus these processes will be highly appreciated. The approach to a solar driven AOP is called solar detoxification.

Egypt is well endowed with a high solar intensity. The annual global radiation is between 7 and $9 \mathrm{GJ} \mathrm{m}^{-2}$ [9]. Many researches in Egypt have used solar energy in different applications, i.e., in the thermoelectric cooling [10] and heating systems powered by a photovoltaic cells [11]. However, it is not used and applied so far in the solar detoxification system. From this point of view, the utilization of solar energy in the photo treatment mineralization as in the AOPs represents an economic source for the UV light. In the present work, the application of different advanced processes; $\mathrm{UV} / \mathrm{H}_{2} \mathrm{O}_{2}, \mathrm{UV} / \mathrm{TiO}_{2}, \mathrm{UV} / \mathrm{TiO}_{2} / \mathrm{H}_{2} \mathrm{O}_{2}$ and $\mathrm{UV} / \mathrm{Fe}^{3+} / \mathrm{H}_{2} \mathrm{O}_{2}$ was studied for the treatment of a model industrial textile wastewater effluent using a solar photo reactor. The results of these AOPs and their kinetic constants were compared.

\section{MATERIALS AND METHODS}

\subsection{MATERIALS}

A simulated industrial textile wastewater was synthetically prepared using Methylene Blue Dyestuff. $\mathrm{Fe}_{2}+$ in Fenton's reagent is prepared by making a solution from $\mathrm{Fe}\left(\mathrm{C}_{2} \mathrm{O}_{4}\right)_{3} \cdot 6 \mathrm{H}_{2} \mathrm{O}$. Hydrogen peroxide was obtained in liquid (30\% by wt) from a commercial supplier. Sulfuric acid is used for adjusting the $\mathrm{pH}$ of the wastewater samples during the photo-Fenton's treatment. In addition, oxalic acid is used to enhance the photo-Fenton's reagent process. $\mathrm{TiO}_{2}$ is used as a catalyst; the formula and molecular weights of all chemicals used in this study are listed in Table 1.

Table 1: Properties of chemicals used in this study

\begin{tabular}{ccc} 
Compound $^{*}$ & Formula & Molecular weight \\
\hline Methylene Blue Dyestuff & $\mathrm{C}_{16} \mathrm{H}_{18} \mathrm{~N}_{3} \mathrm{SCl} .3 \mathrm{H}_{2} \mathrm{O}$ & 373.9 \\
Ferric oxalate & $\mathrm{Fe}\left(\mathrm{C}_{2} \mathrm{O}_{4}\right) 3.6 \mathrm{H}_{2} \mathrm{O}$ & 483.9 \\
Hydrogen peroxide & $\mathrm{H}_{2} \mathrm{O}_{2}$ & 134.01 \\
Titanium dioxide & $\mathrm{TiO}_{2}$ & 79.879 \\
Sulfuric acid & $\mathrm{H}_{2} \mathrm{SO}_{4}$ & 98.08 \\
\hline
\end{tabular}

${ }^{*}$ All the above chemicals are supplied by CIBA specialty chemicals 


\subsection{EXPERIMENTAL METHODS}

The model dyestuff wastewater was treated using a solar photo-chemical reactor. As shown in Fig. 1, the experimental setup is a closed cycle, which consists of a feed/discharge vessel connected to a tubular reactor. This tubular reactor is a quartz glass mounted in the focal line of a parabolic concentrating collector in order to assure that the tubular reactor receives the maximum possible solar radiation. In addition a similar photo-reactor was used to compare the effect of the sunlight with artificial UV light. This experiment was carried out by mounting a UV lamp with a predominant radiation of $450 \mathrm{~nm}$ with output equivalent to $40 \mathrm{~W}$ parallel to the tubular reactor so that its light is distributed evenly on the tubular reactor. This setup is used to carry out indoor experiment.

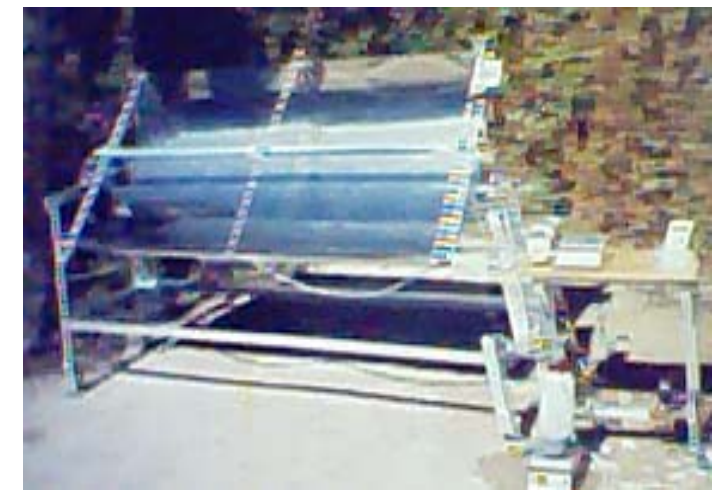

(a) Photo for the experimental setup

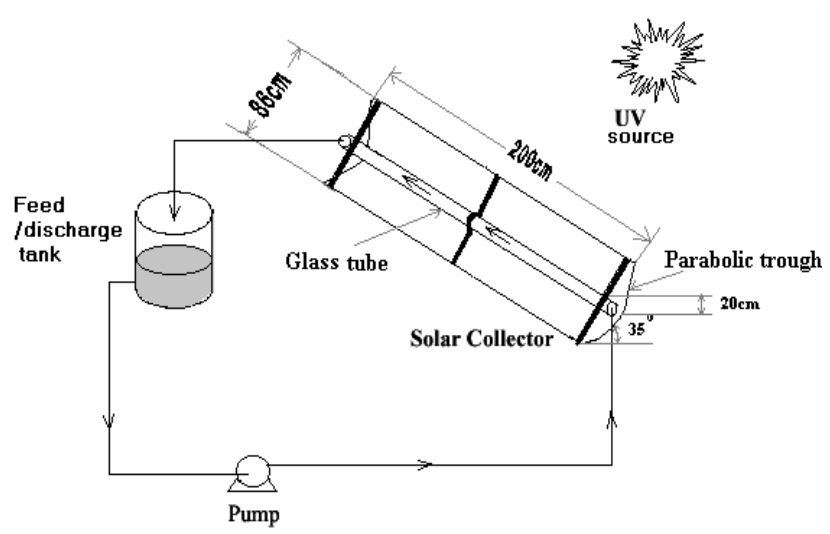

(b) Schematic diagram for the photo-reactor

Fig. 1: Experimental setup

The photo catalyst is added in the feed/discharge vessel after pH adjustment; if it is needed using sulfuric acid. Then, the solution is circulated in the tubular reactor at the required flow rate. The concentration of the samples was recorded every 10 min during the reaction time.

\subsection{Analytical Methods:}

The synthetic wastewater was prepared with different concentrations using Methylene Blue dyestuff and then; if required; the $\mathrm{pH}$ was adjusted by a digital $\mathrm{pH}-$ meter (model PHM62). The concentration of the samples was measured using a Spectrophotometer (SHIMADZU-UV 1601, Model TCC-240A). An Epply Black-andWhite solarimeter, which is connected to a digital millimetre to display the readings as millivolts is used to record the solar intensity during the experiments 


\section{RESULTS AND DISCUSSION}

\subsection{Mineralization of textile wastewater by Different AOPs:}

Using the photo-reactor, different experiments were carried out in order to compare the efficiency of Methylene Blue degradation in homogenous (photo-Fenton and $\mathrm{H}_{2} \mathrm{O}_{2}$ system) and heterogeneous (using $\mathrm{TiO}_{2}$ and $\mathrm{TiO}_{2} / \mathrm{H}_{2} \mathrm{O}_{2}$ as a photo-catalysts) solution. The doses of the different reagents were chosen; after the preliminary study such that it is at the optimum conditions for each case which is corresponding to the maximum reaction efficiency. For homogenous systems, photo-Fenton catalyst concentration was $\left(\mathrm{H}_{2} \mathrm{O}_{2}=40 \mathrm{mg} / \mathrm{l}, \mathrm{Fe}^{3+}=20 \mathrm{mg} / \mathrm{l}\right.$ and oxalic acid $\left.=26 \mathrm{mg} / \mathrm{l}\right)$ and $\mathrm{H}_{2} \mathrm{O}_{2}$ catalyst was $1000 \mathrm{mg} / \mathrm{l}$. For the heterogeneous process the catalysts was added to the pollutant stream in two types. The first is using $\mathrm{TiO}_{2}$ only and the other one is using $\mathrm{TiO}_{2} / \mathrm{H}_{2} \mathrm{O}_{2}$ at concentrations of $1 \mathrm{~g} / \mathrm{l}$ and $(1 \mathrm{~g} / \mathrm{l}$ and $1000 \mathrm{mg} / \mathrm{l})$, respectively.

As illustrated in Fig. 2 the most efficient process in the degradation of Methylene Blue was the photo-Fenton process, where the percentage degradation reached about $98.8 \%$ in only one hour. This is followed by $\mathrm{UV} / \mathrm{TiO}_{2} / \mathrm{H}_{2} \mathrm{O}_{2}$ process which degradation percentage reached $97 \%$, and then the $\mathrm{UV} / \mathrm{TiO}_{2}$ which had a degradation percentage of $68 \%$, and finally the $\mathrm{H}_{2} \mathrm{O}_{2}$ process which had a degradation percentage of $67 \%$, all are compared after one hour of degradation. . It is clear that the initial sudden drop is not markedly pronounced when using $\mathrm{H}_{2} \mathrm{O}_{2}$ only, but the curve is continuing its inclination along the time of experiment, so the degradation continued to reach $89 \%$ after 3 hours. This is to be compared to other curves after only 5 minutes from the exposure time where the degradation in the photo-Fenton process reached $83 \%$ while the final degradation was $98.8 \%$. This was illustrated earlier to be due to the consumption of $\mathrm{H}_{2} \mathrm{O}_{2}$ in the photo-Fenton process in the early period and thus the reaction becomes slower in the remaining period. In the $\mathrm{TiO}_{2}$ process the initial drop in concentration of pollutant is due to the adsorption of the pollutant on the catalyst surface during the initial period. This is in agreement with previous work of Bekblet et al. [12].

In the case of heterogeneous photo catalysis the addition of $\mathrm{H}_{2} \mathrm{O}_{2}$ enhances the photo degradation rate. The comparison declares that the sunlight $/ \mathrm{TiO}_{2} / \mathrm{H}_{2} \mathrm{O}_{2}$ system is more efficient than the sunlight/TiO 2 system because the $\mathrm{H}_{2} \mathrm{O}_{2}$ is considered to be an efficient electron scavenger, which reacts with electrons of the conduction band of $\mathrm{TiO}_{2}$ to generate additional $\cdot \mathrm{OH}$ radicals.

As can be seen the degradation rate of Methylene Blue dyestuff in the photo-Fenton system is higher than in the heterogeneous reactions. To explain these results, the different absorption capabilities of both $\mathrm{Fe}^{3+}$ and $\mathrm{TiO}_{2}$ catalysts have to be taken into account. The $\mathrm{TiO}_{2}$ absorbs the UV light with a wavelength between $300-400 \mathrm{~nm}$ (only about $7 \%$ of the solar irradiation). Furthermore, in homogenous solution the depth of light penetration is high and the contact between pollutant and oxidizing agent is close. 
In both homogenous and heterogeneous processes, the. $\mathrm{OH}$ radicals are mainly responsible for the organic pollutant oxidation. It is thus recommended to use the photo-Fenton process in the mineralization of organic wastewater effluent.

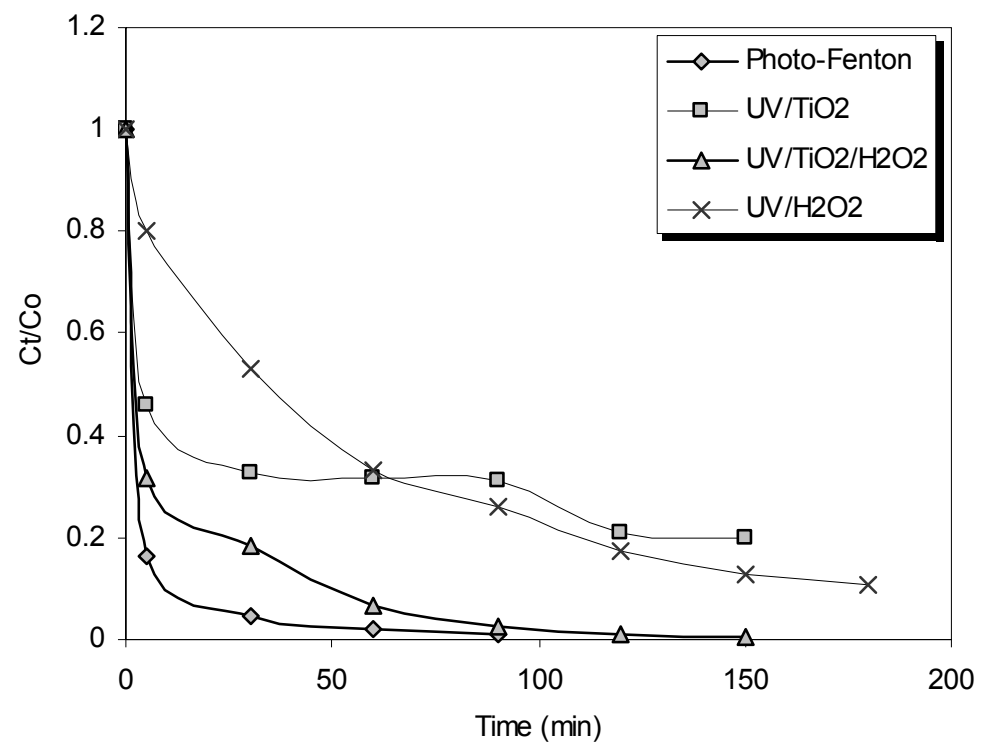

Fig. 2: Evaluation of different AOPs (Model pollutant is Methylene Blue)

\subsection{Kinetics of the photo catalytic disappearance of Methylene Blue in different Advanced Oxidation Processes:}

In order to compare the efficiency of the homogenous and heterogeneous photo catalytic treatment processes, the values of the kinetic rate constants are compared. The kinetic curves in Fig. 3 are of first order as confirmed by the linear transforms shown in the figure with a correlation coefficient of about 0.9 . Values of the first-order rate constants are 0.0421 , $0.031,0.0132$ and 0.0087 are obtained for photo-Fenton, UV/TiO $/ \mathrm{H}_{2} \mathrm{O}_{2}, \mathrm{UV} / \mathrm{H}_{2} \mathrm{O}_{2}$ and $\mathrm{UV} / \mathrm{TiO}_{2}$ processes, respectively. As can be observed, the Methylene Blue degradation rate in the photo-Fenton system is higher than in the heterogeneous reactions as explained.

Examination of the kinetic constant values of Methylene Blue in the sunlight/ $/ \mathrm{TiO}_{2}$ system reveals that it is the lowest one. The rate constant in the $\mathrm{TiO}_{2} / \mathrm{H}_{2} \mathrm{O}_{2}$ system is more than two times higher than in the $\mathrm{H}_{2} \mathrm{O}_{2}$ system. This is due to the addition of $\mathrm{H}_{2} \mathrm{O}_{2}$ to the $\mathrm{TiO}_{2}$ system and its effect in raising the value of the rate constant by three - and- half times.

The highest rate order is that of the photo-Fenton system, this result confirms that the photo-Fenton process is the most efficient for pollutant degradation as discussed before. This result is also accomplished in the previous work of Malato et al. [1] and Parra et al. [13]. 


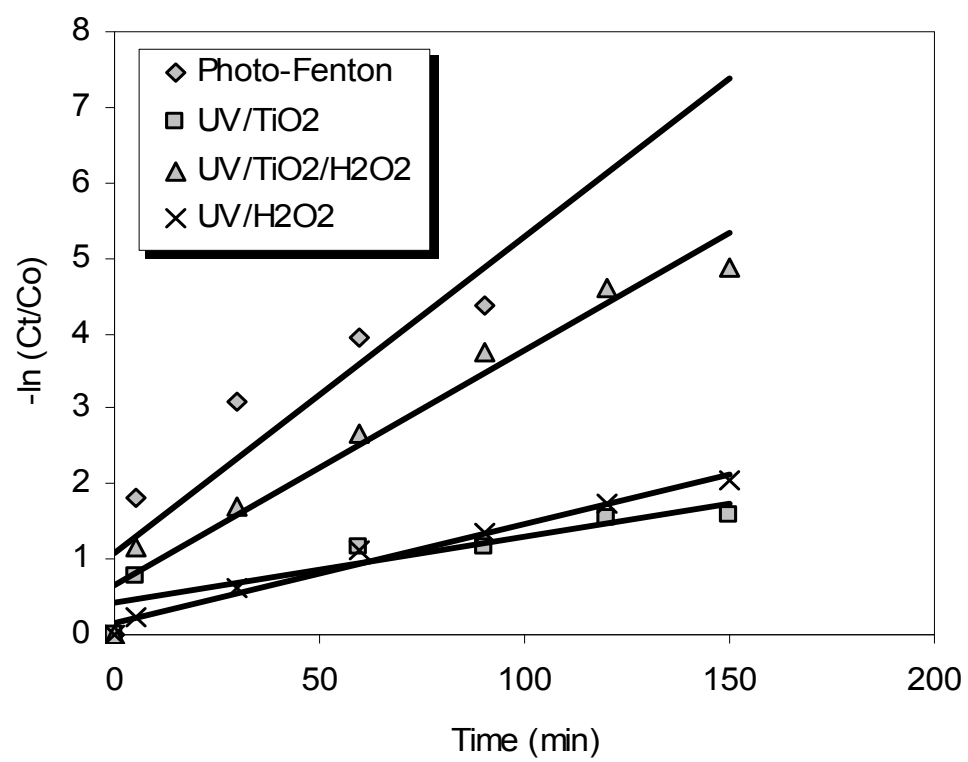

Fig. 3: Plot of the first-order rate constant for different AOPs used for the mineralization of Methylene Blue effluent

The reaction pathway in the photo-Fenton degradation system of the Methylene Blue effluent is a chain of series reactions. The combination between the hydrogen peroxide and the transition metal leads to the formation of the hydroxyl radical according to the following reaction [14]

$$
\mathrm{Fe}^{2+}+\mathrm{H}_{2} \mathrm{O}_{2} \rightarrow{ }^{\bullet} \mathrm{OH}+{ }^{-} \mathrm{OH}+\mathrm{Fe}^{3+}
$$

This reaction is the chain initiation reaction (Neyens et al., 2003b). Although the hydroxyl radicals formation is the key step in the Fenton's reagent, there are other series of chain reactions occur. To illustrate, the ferric ions formed catalyze the hydrogen peroxide to $\mathrm{O}_{2}$ and $\mathrm{H}_{2} \mathrm{O}$, this is known as the Fenton-like reaction. Moreover, additional ferrous and hydroxyl radicals are formed and the reaction is continued. In addition, the $\mathrm{OH}$ can be generated from both photolysis of $\mathrm{H}_{2} \mathrm{O}_{2}$ and photo-reduction of $\mathrm{Fe}(\mathrm{III})$. The additional important reactions which occur include the following equations: [14-16]

$$
\begin{aligned}
& \mathrm{Fe}^{3+}+\mathrm{H}_{2} \mathrm{O}_{2} \rightarrow \mathrm{Fe}^{2+}+\mathrm{OOH}^{\bullet}+\mathrm{H}^{+} \\
& \cdot \mathrm{OH}+\mathrm{Fe}^{2+} \rightarrow \mathrm{Fe}^{3+}+\mathrm{HO}^{-} \\
& \mathrm{Fe}^{3+}+\mathrm{OOH}^{\bullet} \rightarrow \mathrm{Fe}^{2+}+\mathrm{O}_{2}+\mathrm{H}^{+} \\
& \cdot \mathrm{OH}+\mathrm{H}_{2} \mathrm{O}_{2} \rightarrow \mathrm{O}_{2}^{--}+\mathrm{H}^{+}+\mathrm{H}_{2} \mathrm{O}
\end{aligned}
$$

These formed $\mathrm{OH}$ radicals attack the Methylene Blue molecules in the wastewater. The hydroxyl radicals performed the oxidation reaction by the ring opening reactions, which further carry on the mineralisation of the molecule. The results of this study showed clearly that the oxidation process of Methylene Blue was ${ }^{\circ} \mathrm{OH}$ dependent. 


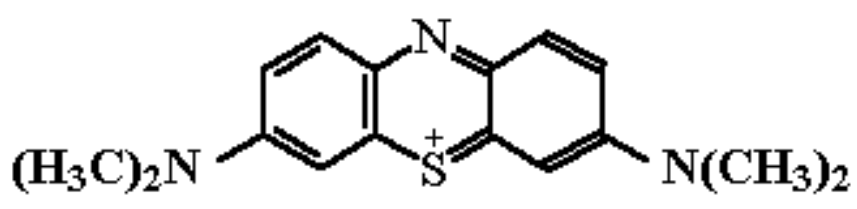

$\mathrm{Cl}^{-}$

Fig. 4: Chemical structural formula of Methylene Blue [17]

\subsection{Cost Estimates:}

To verify the cost effectiveness of the photo-Fenton process the cost of different AOPs, namely sunlight $/ \mathrm{H}_{2} \mathrm{O}_{2}$, sunlight $/ \mathrm{TiO}$, sunlight $/ \mathrm{TiO}_{2} / \mathrm{H}_{2} \mathrm{O}_{2}$ and photo-Fenton/ artificial UV light were compared to photo-Fenton/sunlight reaction. Therefore, the following assumptions were made:

(a) The cost (Egyptian pound, L.E.) of the treatment of $1 \mathrm{~L}$ of the wastewater was used for the comparison.

(b) For laboratory applications, only chemicals and energy costs are considered but investment costs for apparatus and buildings are not included. The prices used in the calculations are listed in Table 2.

(c) Additional operations like filtration; centrifugation will be needed only when using $\mathrm{TiO}_{2}$ catalyst. The cost of these operations is not included in the study since their application highly depends on the special treatment goal and on governmental regulations.

(d) The figures mentioned in the cost estimations are based on the information obtained from the laboratory work.

Table 2: Prices Used in Cost Estimation

\begin{tabular}{ccc}
\hline Item & Unit & Cost, L.E. ${ }^{*}$ unit \\
\hline $\mathrm{H}_{2} \mathrm{O}_{2}(30 \%)$ & $\mathrm{L}$ & 12 \\
$\mathrm{TiO}_{2}$ & $\mathrm{Kg}$ & 800 \\
$\mathrm{Fe}_{2}\left(\mathrm{C}_{2} \mathrm{O}_{4}\right)_{3} .6 \mathrm{H}_{2} \mathrm{O}$ & $\mathrm{Kg}$ & 80 \\
$\mathrm{C}_{2} \mathrm{H}_{2} \mathrm{O}_{4}(99 \%)$ & $\mathrm{kg}$ & 28 \\
$\mathrm{H}_{2} \mathrm{SO}_{4}$ & $\mathrm{~L}$ & 38 \\
Electrical energy & $\mathrm{kWh}$ & 0.2 \\
\hline${ }^{*} 6.20$ L.E. $\approx 1$ US $\$$ (at time of study) & \\
\hline
\end{tabular}


It is noted that artificial UV light in the photo-Fenton process needs higher energy demand and results in lower mineralization percentage. Thus, when using sunlight it seems justifiable to calculate zero energy for the light source (energy used only for pumps).

Assuming that the degradation process is economically feasible at the time when steep reduction of pollutant concentration stops, the time of degradation will be 150 minutes for sunlight $/ \mathrm{H}_{2} \mathrm{O}_{2}, 120$ minutes for sunlight $/ \mathrm{TiO}_{2}, 90$ minutes for sunlight $/ \mathrm{TiO}_{2} / \mathrm{H}_{2} \mathrm{O}_{2}, 120$ minutes for artificial UV/photo-Fenton, and 60 minutes for sunlight/ photo-Fenton. The result of the cost estimate required to reach an economic degree of degradation is shown in Table 3.

Table 3: Cost Estimate for Various AOPs for the Degradation of Methylene Blue Basis: one liter of 5 ppm Methylene Blue solution

\begin{tabular}{|c|c|c|c|c|c|c|}
\hline Process & $\begin{array}{l}\text { Degradation } \\
\text { time, } h\end{array}$ & $\begin{array}{c}\text { Final } \\
\text { economic } \\
\text { degradation } \\
\%\end{array}$ & $\begin{array}{c}\text { Chemicals } \\
\text { costs, } \\
\text { L.E. }\end{array}$ & $\begin{array}{c}\text { Energy } \\
\text { demand, } \\
\text { kWh }\end{array}$ & $\begin{array}{c}\text { Energy } \\
\text { costs, } \\
\text { L.E. }\end{array}$ & $\begin{array}{c}\text { Total } \\
\text { costs, } \\
\text { L.E. }\end{array}$ \\
\hline $\begin{array}{c}\mathrm{H}_{2} \mathrm{O}_{2} \\
\text { (sunlight) }\end{array}$ & 2.5 & $87.2 \%$ & 0.012 & 0.92 & 0.184 & 0.196 \\
\hline $\begin{array}{c}\mathrm{TiO}_{2} \\
\text { (sunlight) }\end{array}$ & 2 & $78.8 \%$ & 0.800 & 0.736 & 0.1472 & 0.947 \\
\hline $\begin{array}{c}\mathrm{TiO}_{2} / \mathrm{H}_{2} \mathrm{O}_{2} \\
\text { (sunlight) } \\
\text { photo- }\end{array}$ & 1.5 & $97.6 \%$ & 0.812 & 0.552 & 0.1104 & 0.922 \\
\hline $\begin{array}{l}\text { Fenton } \\
\text { (artificial } \\
\text { UV) } \\
\text { photo- }\end{array}$ & 2 & $86.6 \%$ & 0.0028 & 0.736 & 0.1472 & 0.150 \\
\hline $\begin{array}{c}\text { Fenton } \\
\text { (sunlight) }\end{array}$ & 1 & $98 \%$ & 0.0028 & 0.368 & 0.0736 & 0.076 \\
\hline
\end{tabular}

\subsubsection{Comparative Cost:}

For the object of comparison, the cost of treatment using different processes is represented in Fig. 4. Examination of the figure indicates that the cost of the photoFenton process represents only $8.28 \%$ of $\mathrm{TiO}_{2} / \mathrm{H}_{2} \mathrm{O}_{2}$ process, $8 \%$ of the $\mathrm{TiO}_{2}$ process, $39 \%$ of $\mathrm{H}_{2} \mathrm{O}_{2}$ process with the use of sunlight and $50.9 \%$ of photo-Fenton process in artificial UV light. Thus, it is concluded that the photo-Fenton process is the cheapest photo-treatment process for treatment of the textile effluents (simulated by a Methylene Blue dyestuff effluent). 


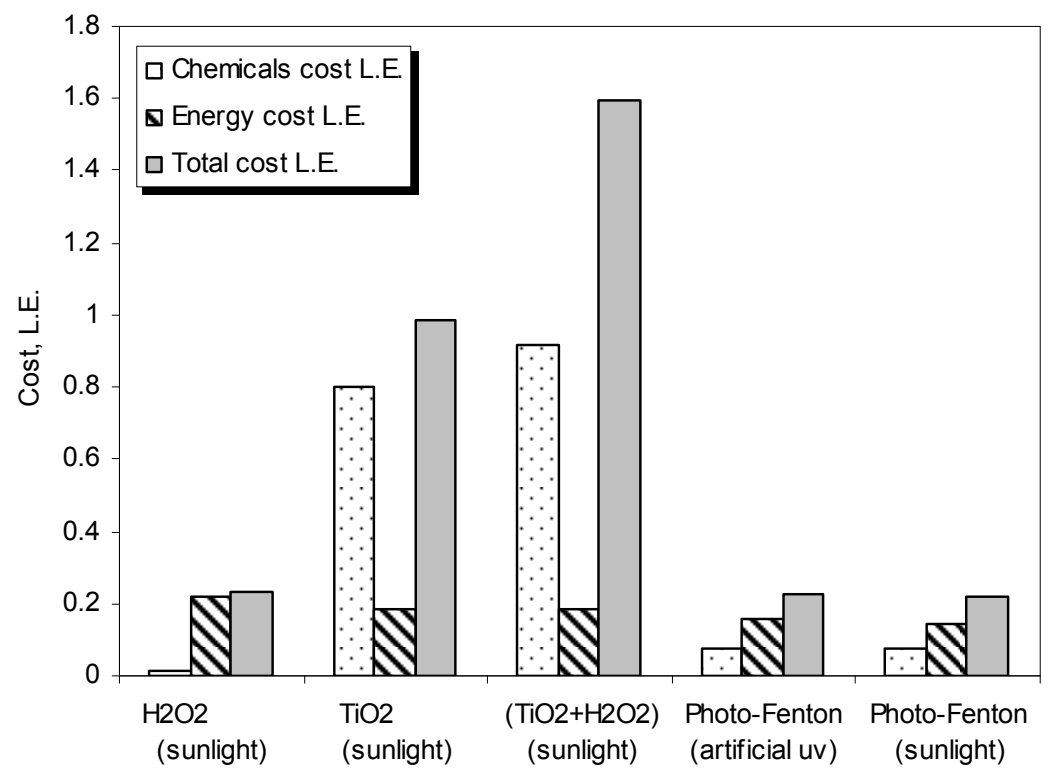

Fig. 4: Comparison of chemicals and energy costs of various AOPs for the mineralization of Methylene Blue

\subsection{Plant Layout:}

Fig. 5 shows a diagram of a photo catalytic plant that can be used for the photoFenton process. The solar collector surface area mainly depends on the specifications of the wastewater stream to be treated (concentration and type of contaminant) and on the irradiation conditions of the plant site. The technique used for $\mathrm{pH}$ adjustment and feeding the catalyst components (ferricoxalate, hydrogen peroxide, oxalic acid) to the treatment unit is shown in Fig. 5. The treated water containing traces of $\mathrm{Fe}$ is stored in a tank in order to separate the iron before disposal and then it is reused, if necessary. The separation of iron is affected by the $\mathrm{pH}$ of the treated water, where a base or an acid is added to adjust the $\mathrm{pH}$ to attain the precipitation of iron hydroxide as shown in Fig. 5 . The supernatant water can be discharged directly and the precipitate can be reused.

The iron hydroxide can be dissolved in highly acidic medium, and the resulting highly acidic iron solution could be a suitable photo-Fenton reagent ready for use, by adding it to the untreated wastewater.

As shown in the previous sections $20 \mathrm{mg} / \mathrm{l}$ of Fe may be enough to perform the treatment process. This means that quite low concentrations of $\mathrm{Fe}$ are originally used. Thus, at the end of the photo-Fenton treatment process, it may not be necessary to remove the remaining iron from the effluent water since it may fit with the standards of wastewater disposal. 


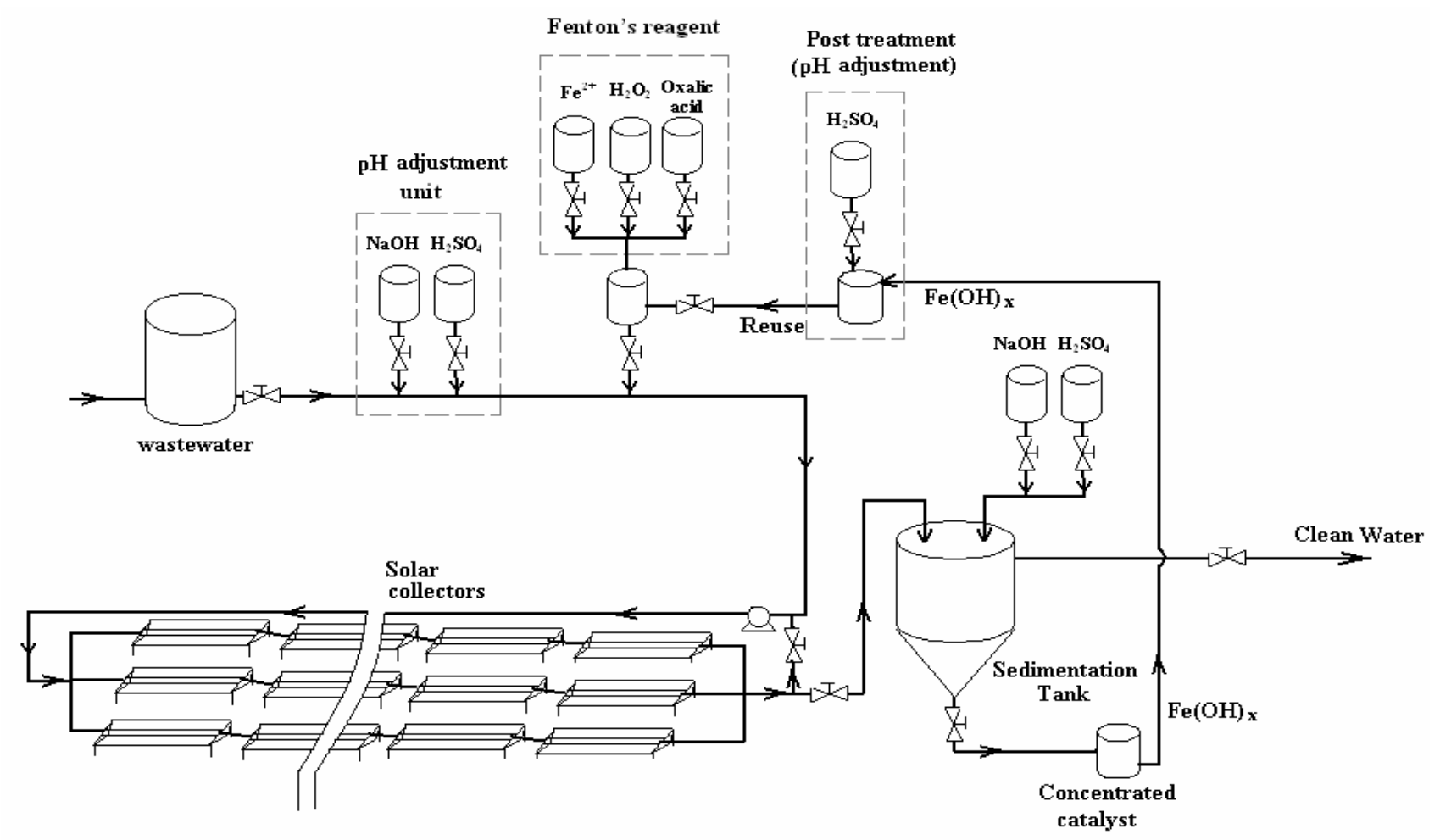

Fig. 5: Simplified diagram for a photo catalytic treatment plant

\section{CONCLUSIONS}

The comparison of percentage degradation of various $A O P s$ including $\mathrm{H}_{2} \mathrm{O}_{2}, \mathrm{TiO}_{2}$, $\mathrm{TiO}_{2} / \mathrm{H}_{2} \mathrm{O}_{2}$, photo-Fenton methods proved that the photo-Fenton process is the most favourable, especially in case of using sunlight. The order was photo-Fenton $>\mathrm{TiO}_{2} /$ $\mathrm{H}_{2} \mathrm{O}_{2}>\mathrm{TiO}_{2}>\mathrm{H}_{2} \mathrm{O}_{2}$. Moreover, the kinetic orders for different AOPs are compared and it is found that the constant of the first order photo-Fenton reaction is the highest one. The kinetic constants were as follows $0.0421,0.031,0.0132$, and 0.0087 for photoFenton, $\mathrm{TiO}_{2} / \mathrm{H}_{2} \mathrm{O}_{2}, \mathrm{H}_{2} \mathrm{O}_{2}$ and $\mathrm{TiO}_{2}$ processes, respectively. Cost estimates for the chemicals and energy needed have shown that the photo-Fenton method is the cheapest available process for the treatment of industrial dye wastewater streams.

\section{REFERENCES}

1. Malato, S.; Blanco, J.; Vidal, A. and Alarcon, D., "Applied studies in solar photo catalytic detoxification: an overview", Sol. Energy, 75, 329-336, (2003).

2. Steverson, E., "Provoking a firestorm: Waste incineration", Environ. Sci. \& Tech., 25, 1419- 1427, (1991).

3. Dempsey, C. and Oppelt, E., "Incineration of hazardous waste: A critical review", Air and Waste, 43, 25-73, (1993). 
4 Bauer, R. and Fallmann, $H$., "The photo-Fenton oxidation- a cheap and efficient wastewater treatment method", Res. Chem. Intermed, 23, No. 4,. 341-354, (1997).

5. Nansheng, D.; Tao, F. and Shizhong, T., "Photodegradation of dyes in aqueous solutions containing Fe(III) hydroxy complex I photo degradation kinetics", Chemosphere, 33 (3), 547-557, (1996).

6. Chen, J.; Wim, H. R. and Harry, B., "Photochemical elimination of phenols in industrial wastewater", Water Sci. \& Tech., 35 (4), 231-238, (1997).

7. Emilio, C. A.; Jardim, W. F.; Litter, M. I. and Mansilla, H. D., "EDTA destruction using the solar ferrioxalate advanced oxidation technology (AOT); Comparison with solar photo-Fenton treatment", J. Photochem. Photobiol. A: Chemistry, 15 (1-3), 121-127, (2002).

8. Will, I. B. ; Moraes, J. E. and Teixeira, A. C., "Photo-Fenton degradation of wastewater containing organic compounds in solar reactors", J. Sep. Purif. Tech., 34 (1-3), (2004).

9. H. M. El-Mashad,W. K.P. Loon, G. Zeeman, "A Model of Sol. Energy Utilisation in the Anaerobic Digestion of Cattle Manure", Biosystems Eng., 84 (2), 231-238, (2003).

10. Khattab, N.M., El Shenawy, E.T., "Optimal operation of thermoelectric cooler driven by solar thermoelectric generator", Energy Conversion and Manag. 47, 407-426, (2006).

11. Abdel-Rehim, Z. S., Fahmy, F. H., "World Renewable Energy Congress VI, Renewables: The Energy for the 21st Century World Renewable Energy Congress VI 1-7 July (2000) Brighton, UK, 2000, 2110-2114, Chapter 451 Heating and Pumping Systems Powered by Photovoltaic for Swimming Pools

12. Bekbolet, M.; Lindener, M.; Weichgrebe, D. and Bahnemann, D., "Photocatalytic detoxification with the thin film fixed bed reactor (TFFBR). Clean up of highly polluted effluent using a novel $\mathrm{TiO}_{2}$-photocatalyst", Sol. Energy, 56 (5), 455-469, (1996).

13. Parra, S.; Malato, S.; Blanco, J.; Peringer, P. and Pulgarin, C., "Concentrating versus non-concentrating reactors for solar photo catalytic degradation of p-nitro toluene-o-sulfonic acid", Water Sci. \& Techn., 44, (5), 219-227, (2001).

14. Plgnatello, J.J., "Dark and photo assisted $\mathrm{Fe}^{3+}$-Catalyzed degradation of chlorophenoxy herbicides by hydrogen peroxide", Environ. Sci. \& Technol., 26, 944-951, (1992).

15. Zhang, H., Choi, H. J., Huang, C., "Optimization of Fenton process for the treatment of landfill leachate, Journal of Hazardous Material", B 125, 166-174, (2005).

16. Spacek, W., Bauer, R., "Heterogeneous and homogenous wastewater treatment- comparison between photo-Fenton photo degradation with $\mathrm{TiO}_{2}$ and the photo-Fenton traction", Chemosphere, 30 (3), 477-484, (1995).

17. http://www.nilechemicals.com/methyleneblue.htm 